\title{
Transcatheter repair of valvular heart disease and periprocedural imaging
}

\author{
Paul Schoenhagen $\cdot$ Jeroen Bax
}

Received: 12 February 2011 / Accepted: 16 February 2011/Published online: 26 February 2011

(C) Springer Science+Business Media, B.V. 2011

Transcatheter treatment of structural heart disease is beginning to provide effective alternatives for selected, high-risk patient populations with symptomatic valvular heart disease.

Transcatheter treatment approaches for valve repair/implantation have developed together with novel imaging approaches, with a particular focus of 3-D imaging acquisition and reconstruction. Periprocedural imaging for planning and procedural guidance is critical, because of the lack of direct exposure of the operative field.

While invasive angiography and echocardiography maintain a central role, novel imaging modalities with 3-D data acquisition have gained increasing importance. This includes computed tomography, magnetic resonance imaging, 3-D echocardiography, and rotational angiography.

This Topical Issue of the journal is focused on transcatheter valvular repair/implantation and associated concepts of peri-procedural imaging. An international group of experts in this rapidly evolving field describe important clinical aspects of the procedure and their relationship to imaging for planning, interventional guidance, and device development.

Similar to the need for further evaluation of the procedures itself, the impact and role of imaging will need to be evaluated in future clinical trials [1].

Conflict of interest None.

\section{References}

1. Leon MB, Piazza N, Nikolsky E, Blackstone EH, Cutlip DE, Kappetein AP, Krucoff MW, Mack M, Mehran R, Miller C, Morel MA, Petersen J, Popma JJ, Takkenberg JJ, Vahanian A, van Es GA, Vranckx P, Webb JG, Windecker S, Serruys PW (2011) Standardized endpoint definitions for transcatheter aortic valve implantation clinical trials: a consensus report from the valve academic research consortium. Eur Heart J 32:205-217
P. Schoenhagen $(\bowtie)$

Cleveland Clinic, Cleveland, OH, USA

e-mail: schoenp1@ccf.org

J. Bax

Leiden University Medical Center, Leiden,

The Netherlands 